\title{
Atualizando, juntando e esticando a universidade: considerações sobre a possibilidade de uma pluriversidade ${ }^{1}$
}

\author{
Maria do Socorro Pimentel da Silva ${ }^{2}$ \\ Alexandre Herbetta ${ }^{3}$
}

\begin{abstract}
RESUMO: O presente texto apresenta considerações iniciais acerca da consolidação de uma nova base epistêmica, acessada para se pensar a educação escolar indígena e a universidade. Tal situação tem relação com a emergência de um novo repertório conceitual, constituído na dinâmica de um diálogo intercultural crítico. A situação é apresentada no contexto do Núcleo Takinahaky de Formação Superior Indígena da Universidade Federal de Goiás. Um dentre vários cursos de licenciatura intercultural criados para a formação de professores indígenas. Isto no âmbito do movimento indígena organizado especialmente na década de 1980, de legislação elaborada posteriormente e da efetivação de políticas públicas sobre o tema, especialmente na década de 2000. Neste sentido, a experiência em tela, específica a este espaço, busca apontar reflexões mais gerais e interessantes acerca de modelos de educação escolar, trazendo reflexões sobre a interculturalidade, assim como propõe uma reflexão sobre estratégias políticas decoloniais por meio da educação escolar e da universidade.
\end{abstract}

Palavras-chave: Educação. Escola. Descolonização. Epistemologias.

\section{Updating, joining and stretching the university: considerations about the possibility of a pluriversity}

ABSTRACT: The present text points out initial considerations about the consolidation of a new epistemic base, accessed to think about indigenous school education and the university. This situation is related to the emergence of a new conceptual repertoire, constituted in the dynamic of a critical intercultural dialogue. The situation is presented in the context of the Takinahaky Center of Indigenous Higher Education of the Federal University of Goiás. One of several intercultural licentiate courses created for indigenous teachers training. This was done in the context of the indigenous movement organized especially in the 1980s, on the legislation elaborated later and in the implementation of public policies, especially in the decade of 2000 . In this sense, this experience, particular to this space, seeks to point out general and interesting reflections about models of school education, reflecting on interculturality, as well as proposes a reflection on decolonial political strategies through school education and university.

Keywords: Education. School. Decolonization. Epistemologies.

${ }^{1}$ Uma versão reduzida deste texto foi publicada em HERBETTA, Alexandre; PIMENTEL DA SILVA, Maria do Socorro. EDUCAÇÃO INTERCULTURAL E INTEREPISTÊMICA: DESAFIOS POLÍTICOS PARA (E A PARTIR) DA ESCOLA INDÍGENA: Educação indígena e interculturalidade: um debate epistemológico e político = Educación indígena e interculturalidad: un debate epistemológico y político/ Mariano Báez Landa; Alexandre Ferraz Herbetta (Org.). - bilíngue - Goiânia: Editora da Imprensa Uni- versitária, 2017.

2 Doutora em Linguística Aplicada ao Ensino de Línguas pela Pontifícia Universidade Católica de São Paulo. Professora Associada pela Universidade Federal de Goiás, atuando no Curso de Licenciatura Intercultural - Núcleo Takinahaky.

${ }^{3}$ Doutor em Antropologia pela Pontifícia Universidade Católica de São Paulo. Professor Adjunto pela Universidade Federal de Goiás, atuando no Curso de Licenciatura Intercultural - Núcleo Takinahaky. 
Este texto reflete sobre possibilidades decorrentes da criação e elaboração de alguns espaços inovadores de democratização em algumas universidades brasileiras, fazendo com que as mesmas recebam populações culturalmente distintas e historicamente excluídas da academia, como indígenas e quilombolas. Dessa forma, simultaneamente, constituam também espaço de produção de conhecimento e de novas relações de convivência a partir de outras dinâmicas e epistemologias. No mesmo contexto, percebe-se muitas vezes a reprodução de mecanismos que limitam ou mesmo excluem a possibilidade de uma universidade mais democrática.

Desde a década de 2000 no Brasil, há programas acadêmicos que tomam como base a noção de interculturalidade crítica e buscam estabelecer diálogo entre várias áreas do saber. Muitos desses programas têm relação direta com cursos de licenciatura voltados à formação de professores e professoras indígenas. Outros programas buscam promover outras relações, como a "Universidade das Quebradas", criada na Universidade Federal do Rio de Janeiro, que tem como objetivo estabelecer diálogo entre academia e periferia da cidade. Segundo eles "é ainda raro na academia o desenvolvimento de espaços permanentes de diálogo, capacitação e criação compartilhada entre segmentos culturais diversificados" (https://www.universidadedasquebradas.co $\mathrm{m} /$ ).

E o "Encontro de Saberes", desenvolvido na Universidade de Brasília, mais especificamente no Instituto Nacional de Ciência e Tecnologia de Inclusão no Ensino Superior e na Pesquisa (INCTI), com ramificações na Universidade Federal de Minas Gerais, que estabelece transformações importantes na universidade através da entrada de mestres da cultura tradicional na academia com o mesmo status de docentes não indígenas/quilombolas. A proposta do mesmo é

propiciar um espaço de experimentação pedagógica e epistêmica no ensino capaz de inspirar resgates de saberes e inovações que beneficiem a todos os envolvidos - estudantes, mestres e professores. Trata-se de um desafio de grandes proporções devido ao verdadeiro abismo que separa os dois mundos que pretendemos colocar em diálogo: o mundo acadêmico, altamente letrado e centrado exclusivamente nos saberes derivados das universidades ocidentais modernas; e o mundo dos saberes tradicionais, centrado na transmissão oral e que preserva saberes de matrizes indígenas e africanas e de outras comunidades tradicionais, acumuladas durante séculos no Brasil (http://www.inctinclusao.com.br/encontr o-de-saberes/encontro-de-saberes)

Esses programas apoiam-se na ideia de produzir um "conhecimento pluriversitário", o qual segundo Dietz, Guilherme e Sousa Santos (2016, p. 201) "promove os saberes ecológicos, plurais e contra-hegemônicos". Para Sousa Santos "um projeto societário alternativo ao capitalismo global atribui às universidades uma participação ativa na coesão social, no aprofundamento da democracia, no combate à exclusão social, à degradação ambiental e na defesa da diversidade cultural" (2005, p.30).

A ideia deste texto é tratar do que vem sendo chamado "nova base epistêmica" entre professores e professoras indígenas e não indígenas do Núcleo Takinahaky de Formação Superior Indígena (NTFSI) da Universidade Federal de Goiás (UFG). Isto, no 
contexto de reflexão e pesquisa nos campos de estudos da educação intercultural, da educação escolar indígena e da universidade brasileira.

Esta nova base epistêmica busca transformar a marcante elitização da universidade brasileira, no caso da UFG, baseada na noção de colonialidade do saber. Para Vitarelli, tratando das universidades latinoamericanas

algumas universidades públicas aceitaram o desafio e lançaram, na década recente, várias formas de pensar sobre essa nova realidade. Embora o currículo seja o centro do tratamento do assunto, para nós nessa oportunidade o que nos interessa mostrar é o lado sociopolítico que inaugura outras práticas e modos de agir (2017, p.46).

Ela constitui ainda e aponta para uma política educacional inovadora, que segundo o PPP - Projeto Político Pedagógico do Curso de Licenciatura em Educação Intercultural da UFG, parte integrante do NTFSI, "rompeu com a (educação escolar) anterior, que visava à integração gradativa e 'harmônica' dos índios à sociedade não-indígena" (PPP, 2006, p. 8, grifo nosso). É uma base ainda, entretanto, em estágio inicial de construção.

Neste cenário, o conjunto de atividades produzidas no NTFSI como os projetos extraescolares, os relatórios de estágio docência, os relatórios de projetos como o PIBIDDiversidade, da Ação 'Saberes Indígenas na Escola' (FNDE), que se compõe de pesquisa e formação continuada, priorizando-se a alfabetização, o letramento em línguas indígenas e na língua portuguesa e artes verbais, os seminários e reuniões das etapas de estudo em Goiânia e em $\mathrm{TI}$ - Terra Indígena, que serão apresentados ao longo do texto, constituem material complexo e rico a ser analisado.

É a partir deste material, inclusive, que se faz necessário pensar em uma nova base epistêmica para a educação escolar indígena, para a dinâmica do NTFSI e para a universidade. Busca-se aqui, portanto, tomar "categorias e epistemologias endógenas a sério, com foco na produção de conhecimento", assim como Oyewumi (2016, p. 1) faz em sua análise dos Yourubá do sudeste nigeriano. Para ela deve-se explorar "até que ponto os conceitos, ideias e linguagem indígenas são levados em conta na pesquisa acadêmica" (Ibidem).

Como se verá, ainda, tal base é fruto de um diálogo intercultural, no qual emerge um novo repertório conceitual para se pensar a educação escolar, a universidade e o mundo. Para Wallerstein, "cá estamos nós: à beira de uma reestruturação epistemológica fundamental, uma reunificação de métodos de pesquisa nos diferentes campos do conhecimento" (2004, p. 52).

Tais princípios constituem também o que se pode chamar de pensamento-outro. Nas palavras de Mignolo, devemos "buscar um "pensamento outro" que seja, precisamente, o pensamento que decorre da exterioridade colonial, da colonialidade do Ser e da necessidade de contemplar a descolonização como figura central na imaginação de futuros possíveis" (MIGNOLO, 2001, p. 37, tradução dos autores).

\section{NTFSI}

O Núcleo Takinahaky de Formação Superior Indígena constitui espaço de pesquisa e formação no campo da educação escolar indígena e da educação intercultural. Cons- 
titui também a possibilidade de acesso e permanência de indígenas no ensino superior. Existe há onze anos e surge como parte de uma política de formação superior indígena demandada pelo movimento indígena desde a década de 1980. Esta política pública, assim como outras, busca ressaltar práticas de autonomia em detrimento da política indigenista anterior baseada na noção de tutela e integração. Para Luciano Baniwa (2014), a ideia era transformar o índio em um cristão e abrir espaço para a exploração mercantil.

O NTFSI é constituído por curso de graduação e de pós-graduação no nível de especialização. Atualmente, conta com cerca de 300 professores e professoras indígenas dos estados de Goiás, Mato Grosso, Tocantins e Maranhão, pertencentes a 24 distintas etnias, entre elas, os Krahô, Apinajé, Javaé, Karajá, Guarani, Xambioá, Canela, Gavião, Guajajara, Juruna, Krikati, Tapirapé, Xerente, Mehinako, Kamaiurá, Kayapó, Kuikuro, Timbira, Waurá, Xavante, Xacriabá e Tapuia. Há cerca de 150 professores indígenas formados no nível da graduação e 100 no nível da especialização.

O NTFSI buscou se formar e tenta se desenvolver sempre em relação às epistemologias indígenas. O curso tem sua dinâmica voltada para o diálogo intercultural, o qual referencia o PPP do mesmo, a matriz curricular e as práticas pedagógicas produzidas. Cada professor indígena cursa uma matriz curricular básica de dois anos e uma matriz específica de mais três, quando opta por se aprofundar, de modo transdisciplinar, nas áreas da linguagem, natureza e cultura.

As aulas do NTFSI são ministradas em quatro etapas ao longo do ano. Duas nas respectivas aldeias e duas em Goiânia. As aulas de Goiânia são baseadas na noção de tema contextual, buscando se afastar da disciplinarização do conhecimento (HERBETTA, 2016). Conforme Pimentel da Silva (2013), os temas contextuais rompem com a tendência disciplinar de lidar com os conhecimentos. Desse modo, segundo a auto$\mathrm{ra}$, os saberes indígenas entram na escola não pelos cânones hegemônicos da cientificidade tradicional, mas pela liberdade de se produzir outras contextualidades epistêmicas.

A nova base epistêmica aponta, portanto, para um pensamento apto a perceber as ligações, as interações, as implicações mútuas, mas, ao mesmo tempo, apto em perceber a diferenciação e a oposição entre os saberes. É o que Walsh chamaria de interculturalidade crítica. Segundo ela, "o projeto de interculturalidade crítica é proposto como um pensamento "outro" que se afirma na América Latina como um projeto alternativo de natureza ética, ontológica, epistêmica e política" (2013, p. 74, tradução dos autores).

Além da interculturalidade crítica, as noções de contextualização, problematização e transdisciplinaridade são centrais para a movimentação do curso. A interculturalidade é baseada, sobretudo, na ideia de que em um diálogo simétrico entre índios e não índios, deve emergir uma outra forma de se perceber e produzir o mundo - uma nova base epistêmica. A contextualização tem como base a noção de que a situação pedagógica deve ter relação direta com a questão indígena contemporânea e a educação escolar indígena deve estar plenamente conectada às demandas das respectivas comunidades.

A transdisciplinaridade busca ser praticada a partir da ideia de que o currículo escolar é formado por temas contextuais - e não 
disciplinas -, quais sejam, temas que pertencem ao universo cultural e demandas de cada um dos povos indígenas e que não recortam o saber, mas os vivem de forma associada e conectada. Esta dinâmica forma um currículo pautado nos eixos da solidariedade, sustentabilidade e diversidade, e oposto às ideias de fragmentação dos saberes, de homogeneização social e de universalização do conhecimento, implícitas na noção de disciplina.

Simultaneamente, os professores indígenas tentam aplicar paulatinamente a mesma noção de tema contextual em suas escolas indígenas, constituindo, inclusive, seus currículos com base nela. O projeto extraescolar de Julio Kamêr Apinajé (2013), por exemplo, tem como centro a ideia de que para se proteger o território Apinajé das queimadas e assim manter seus recursos naturais protegidos e garantir sua sustentabilidade, é preciso, entre outras coisas, cantar as músicas tradicionais. A partir daí, Kamêr cria práticas pedagógicas relacionadas ao tema, e aponta para sua importância na matriz curricular nativa, como será visto com mais detalhes adiante.

\section{COMITÊS: MODOS COLETIVOS DE PRO- DUÇÃO DE NOVOS PARADIGMAS}

A proposta em tela, como mencionado, é a de atuar com base em um pensamentooutro, evidenciado a partir de uma relação simétrica com os saberes indígenas e chamado aqui de nova base epistêmica. Nesta direção, as atividades do núcleo buscam pautar-se em modos pedagógicos distintos ou não usuais na universidade brasileira. Um dos elementos centrais na dinâmica em questão é o trabalho coletivo. As atividades já mencionadas, assim como outros assun- tos, tais como a logística de chegada de indígenas para a etapa de estudos em Goiânia e vice-versa, assim como questões pessoais, são tratadas no âmbito do que se chama: comitê.

Este, é composto pelo grupo de professores e professoras indígenas pertencentes a um povo e por um ou dois professores não indígenas. O comitê reúne-se regularmente nas etapas a fim de tratar dos temas supracitados. E mantém contato ao longo do ano entre as etapas, organizando eventos e outras atividades. O comitê é constituído igualmente a partir da participação dos sábios da comunidade. São eles que legitimam ações e políticas estabelecidas nos grupos, assim como determinam demandas e atividades importantes para o desenvolvimento das atividades do NTFSI. Acabam também por criar uma rede entre gerações de uma mesma população e mesmo entre os distintos povos, já que por vezes professores de um comitê participam nas atividades de outros.

As atividades desenvolvidas neste espaço buscam fortemente contribuir para a construção de uma educação diferenciada, assim como para o fortalecimento do NTFSI. Como se pode notar, a dinâmica do comitê é central para a constituição da nova base epistêmica em tela, já que tem como objetivo produzir pesquisa/conhecimento acerca de temas relevantes para suas comunidades. $E$, em seguida, aplicar tais conhecimentos em sala de aula, refletindo sobre suas pedagogias e propondo a produção de material didático diferenciado.

Nesta direção, o projeto extraescolar de Rogério Dias Apinajé teve como tema as novas lideranças Apinajé. Segundo ele, as lideranças atuais têm a ver com a juventude, com a escrita e com o domínio do portu- 
guês. Para Rogério, os caciques mais antigos não conseguiam mais acompanhar as mudanças contemporâneas. Nas palavras dele, tempos "atrás tinha uma reunião em Brasília, nenhum queria. Tinha medo.... o cacique participa de reunião, com a comunidade, no pátio. Tem muitos deles que tem medo de enfrentar o documento" (Relatório PIBID-Diversidade, Comitê Apianjé-Krahô, 2012, p.2).

Em sala de aula, Rogério buscou descrever as cerimônias de nomeação de cacique, as principais características do líder e as histórias dos grandes líderes Apinajé, como Tekator e Matuk - atuais nomes das escolas. Seu objetivo é que as crianças valorizem mais o papel dos líderes, já que estes buscam as melhorias para as comunidades, inclusive na educação. Ele ressalta, então, a relação atual entre liderança e educação.

\section{PROJETOS EXTRAESCOLARES}

O projeto extraescolar é um componente central na dinâmica do NTFSI e, consequentemente, na formulação de uma nova base epistêmica. Ele é produzido nos três anos de matriz específica do curso, obrigatoriamente na língua materna e é defendido na comunidade do acadêmico. Além disso, a banca de defesa conta com a participação de professores e professoras do NTFSI, assim como dos anciãos e anciãs do lugar.

Estas práticas, inovadoras em universidades brasileiras, parte de uma política linguística e epistêmica que busca valorizar os saberes locais e registrá-los nos códigos próprios de cada população, descolonizando a noção de que o idioma português e os saberes não indígenas são os únicos espaços possíveis de se registrar conhecimentos científicos.
O desenvolvimento do projeto extraescolar é baseado na sistematização de um saber intra e intercultural e seu tema é decidido a partir de demandas comunitárias identificadas através do diálogo estabelecido - pelo núcleo e acadêmicos - com cada comunidade (nos comitês). A atividade em tela atua igualmente como um processo de letramento em língua indígena, desvelando saberes às vezes esquecidos ou não mais praticados. Segundo os professores indígenas do NTFSI, o projeto extraescolar é parte de um processo de atualização cultural.

Note-se que o sentido de atualização cultural indica o foco em uma matriz curricular cultural. Nela, busca-se a pesquisa sobre a própria lógica cultural e o uso deste conhecimento e de outras metodologias na escola. Neste sentido, estimula-se o jovem a aprender e refletir sobre sua própria cultura. Isto em relação ao mundo contemporâneo e ao contato interétnico.

Segundo Júlio Kamer,

este projeto justifica-se na necessidade do resgate e fortalecimento da cultura e território Apinajé, com a valorização e preservação da cultura, língua e costumes presentes no cotidiano de nossas comunidades. Através do projeto nós do povo Apinajé poderemos desenvolver os nossos conhecimentos para executá-lo junto com as comunidades, portanto garantimos nossas sustentabilidades socioculturais dentro das nossas comunidades das aldeias, para levar informações sobre a importância da cultura e do território Apinajé (Etapa de Estudos em Terra Indígena Apinajé, 2012).

O projeto extraescolar de Kamêr é intitulado "Sustentabilidade Panhi: relações entre queimadas e cantorias no território Apinajé". 
Neste trabalho, Júlio busca, a princípio, definir em termos Apinajé o que é sustentabilidade (XAHTÃ MẼ PAHTE AMNHĨ NHĨPÊX HO HIHTỲX). Ele aponta para uma relação intrínseca e não dicotômica entre cultura e natureza ou entre cantos e queimadas.

Júlio identificou as queimadas como o grande problema do território Apinajé. Isto porque, segundo ele, elas saíram do controle dos próprios e são manejadas por não indígenas, destruindo ano a ano boa parte do território. Com isto, perde-se nas palavras de Kamêr, também, boa parte dos recursos naturais, responsáveis pela criação da cultura. Para Júlio, então, não se pode olhar para o território sem olhar para a cultura e o sujeito. Sua proposta é fazer com que os cantos, poderosos elementos da cultura e registro dos recursos naturais, mitiguem a destruição do território.

Há outros projetos extraescolares que seguem a mesma perspectiva, definindo um processo de atualização cultural.

Dodanin Piiken Krahô (Etapa de estudos em Terra Indígena Krahô, 2013) trabalhou em seu projeto o tema dos artesanatos. Segundo ele, o modo de vida na cultura Krahô tem sofrido muitas mudanças com a interferência da modernidade, o que se pode ver através do uso dos objetos industrializados, fáceis de conseguir. Para Piiken, "nos dias atuais, quase não usamos mais a esteira, o cofo, o moco, entre outros. São poucas as pessoas que ainda sabem fazê-los porque os jovens não querem praticar a nossa cultura. Sendo assim, estamos perdendo o que os nossos velhos nos ensinaram" (idem).

Piiken faz uma interessante relação entre o artesanato e a cultura. Para ele, sem a esteira, por exemplo, não há casamento, se não há casamento não há mais índio, se não há mais índio não há cultura. Logo, sem es- teira, não há Krahô.

No seminário "Práticas escolares" apresentado no Núcleo Takinahaky na etapa de janeiro de 2012, a ideia de atualização cultural é articulada a outras concepções, dando mais profundidade à expressão. Nas imagens elaboradas para a apresentação, o pátio foi um tema recorrente, sendo espaço de atividades que envolvem idosos, adultos e crianças. Nas imagens citadas, ainda, a ação realizada no pátio parecia ser o motivo central. Percebe-se que o movimento no espaço é o modo adequado de conhecer.

Isto fica claro quando Roberto Cahxêt Krahô diferencia a escola indígena e a não indígena. Para ele, "a escola do não indígena é só teoria e a escola indígena é na prática... (ela) não aprisiona os alunos, é uma escola livre... o aprendizado que vem do tocar, do sentir, de dançar, de cantar, de fazer as coisas" (Relatório PIBID-Diversidade, Comitê Apinajé-Krahô, 2012, p.2).

O projeto extraescolar de Cahxêt tratou do tema dos esportes tradicionais, os quais evidenciam a disposição para a ação - o movimento. Além disso, Roberto buscou relacionar o tema central a uma série de outros assuntos. Para ele, trabalhar com a corrida de tora, no pátio, significa tratar também do resguardo, do sistema de nominação, do parentesco, das festas, da alimentação, da saúde e de uma série maior de temas relacionados à vida Krahô, a partir de uma dinâmica transdisciplinar. Seu objetivo foi o de estimular o jovem a vivenciar e refletir sobre sua identidade.

Os relatórios de estágio docência de Renato Yahé Krahô corroboram o exposto. Lá pode se ver que para o autor, a produção do conhecimento deve envolver a participação de alunos, professores e comunidade - mobilizando toda a aldeia e saindo da sala de 
aula. O aluno é visto como sujeito do conhecimento - e é a partir da açãomovimento deste sujeito que se dá a aprendizagem. Segundo Renato, a escola deve "multiplicar os conhecimentos", o que se dá pela ampliação das relações cotidianas, isto porque "quem está ouvindo está sendo conscientizado ao ouvir e depois vai divulgar o que ouviu: estica a divulgação" (Etapa de estudos em Terra Indígena Krahô, 2013).

Renato Yahé Krahô criou na Escola 19 de abril um projeto extraescolar relacionado ao alcoolismo. Segundo o mesmo, trata-se de tema relativamente novo e que causa grandes transformações na comunidade. Partindo deste cenário, os alunos foram motivados a sair da sala de aula e a percorrer a aldeia, pesquisando os casos de alcoolismo. Em seguida deveriam, a partir da pesquisa prévia, produzir cartazes para serem expostos em uma reunião comunitária na escola. Desta forma, os alunos produziram conhecimento acerca do tema - movimentandose - difundindo-o pela comunidade, relacionando as diferentes gerações e tomando um pouco mais de consciência acerca das consequências do uso do álcool.

Esta relação entre a aldeia e a cidade, que diz respeito também ao contato interétnico, é bastante tratada em outros projetos extraescolares. $\mathrm{O}$ trabalho de Emílio $\mathrm{Ni}$ nho Apinajé (2016), por exemplo, busca pesquisar o sistema de coleta e exploração econômica do babaçu, recurso natural tradicional na aldeia Mariazinha. Ele propõe-se, então, a entender como o babaçu é explorado nos últimos tempos, o que tem relação com a presença de uma empresa não indígena na aldeia e a entender como funciona o sistema capitalista - mas do ponto de vista Apinajé. Em seguida, Emílio quer registrar quais são os modos tradicionais de explora- ção do babaçu. Através da comparação, busca levar para a escola o tema do contato interétnico e da exploração econômica. Seu objetivo maior é produzir um livro didático acerca do tema.

Em relação a temas derivados do contato interétnico e que tenham relação com o modo tradicional de ser, a saúde tem grande destaque. Em alguns projetos a ideia é a de que com as transformações advindas do contato interétnico a saúde indígena passa por um momento delicado. Davi Wamimen Chavito (2016) trabalha com o tema da saúde. Seu trabalho intitula-se "Saúde contemporânea Apinajé: origens, razões e impactos do alcoolismo e da obesidade entre os Panhi". Segundo ele, atualmente o álcool é considerado como uma nova doença do mundo globalizado, chamada Síndrome, que ataca diretamente o organismo das pessoas e leva até a morte.

Davi conta em seus relatos que a questão do alcoolismo dentro do território Apinajé é um dos fatores que mais preocupam a comunidade desde a década de 80 . Para Wamimen, as causas do uso abusivo de álcool são: "1. mal-estar, 2. raiva, 3. discussão com suas famílias, 4. aliviar a dor; e as consequências são: 1 . destruir as comunidades indígenas, 2. não conseguir trabalhar para sustentar suas famílias, 3 . passar necessidades todos os dias por falta de alimentação na roça de toco tradicional, 4. destruir o organismo, 5. destruir a cultura" (WAMIMEN, 2016, p.5).

Desta forma, ele estabelece uma lógica associativa similar à de seus colegas. $\mathrm{O}$ uso abusivo da bebida pode mesmo acabar com a diferença cultural. Tal assunto vem sendo objeto de discussão dos mais velhos no pátio e chegou a ser tema da escola, graças ao trabalho de Davi. 
Como se pode ver, os projetos extraescolares possuem enorme riqueza e promovem transformações nas comunidades em questão. Os professores referidos tratam de suas demandas comunitárias, a partir do conhecimento pesquisado na comunidade e das relações com outros saberes para produzir novo conhecimento e novas metodologias de ensino; para se produzirem como melhores professores e, consequentemente, produzirem uma nova escola indígena que possa, assim, sustentar seus mundos com equilíbrio e qualidade de vida. É o que chamam de atualização cultural.

\section{ATUALIZAÇÃO DA CULTURA}

A noção de base epistêmica, como se pode notar, tem relação com uma concepção particular de cultura, a qual parece ser muito importante para a efetivação desta outra escola, pensada pelos professores e professoras que cursam o NTFSI. Ela é, inclusive, a base da matriz curricular proposta nos Projetos Políticos Pedagógicos (PPP) que estão sendo produzidos no âmbito do curso de especialização do núcleo.

O conceito de cultura é central quando se fala da educação escolar indígena - e da universidade. Os professores e professoras indígenas sabem disso e expressam tal situação apontando para novos sentidos constituídos a partir de seus próprios códigos. Nesta direção, deve-se notar que, conforme Coelho e Souza,

quando usam nossa palavra - ou alguma tradução engenhosa dela - eles estão produzindo um objeto que significa sua relação conosco, mas trata-se ainda da produção deles: o que eles devem estar fazendo - eles não tem alternativa - não é objetificar sua cultura (sem aspas) por meio de nosso conceito, mas sua relação conosco por meio dos conceitos deles (2010, p. 112).

Atualizar a cultura neste discurso parece apontar para noções importantes acerca da ideia de cultura, que como se viu é central para a descolonização da escola e do mundo.

Em primeiro lugar, deve-se destacar que a expressão traz a ideia da conexão entre elementos e domínios, apontando para outras epistemologias. Para Kamêr (2013), como mencionado, para se mitigar os efeitos das queimadas deve-se cantar músicas tradicionais, já que o território está ligado a recursos naturais, que estão conectados aos artesanatos, à alimentação, aos cantos e aos sujeitos do grupo. Pode-se pensar, inclusive, que a partir desta noção de cultura não há uma divisão estanque e dicotômica entre natureza e cultura.

Em seguida, deve-se falar que o sentido da expressão aponta também para um modo de convivência, baseado na prática cultural, que tem a ver, como dizem, na prática de regras convencionais de socialidade. Busca-se fazer com que a escola trabalhe, mais do que com conteúdos substantivos e concretos, como a alimentação, a música e a dança, por exemplo, com dinâmicas de relação. Obviamente tais dinâmicas tratam dos itens citados, mas de uma perspectiva relacional.

Para os Tapuia, da Escola Estadual Indígena Cacique José Borges, construída em 2004, por exemplo, a dinâmica de se repensar a educação escolar aponta principalmente para o processo de atualização cultural. Para Wellington Tapuia, "não valorizávamos tanto os conhecimentos, achávamos 
que tínhamos que reinventar/revitalizar, percebemos que eles sempre estavam ali, de forma adormecida. Com o PPP eles vão tá circulando na aldeia (os saberes)" (Etapa de Estudos da Especialização Educação Intercultural e Transdisciplinar, 2014).

Segundo Wahuká Karajá, em relação ao processo "há muitas curvas e ressacas do rio que tem nomes e por isso a escola deveria procurar resgatar esse conhecimento para poder fortalecer a educação escolar com a cultura Karajá, porque ali tem nomes de guerreiros e de avos e antepassados e ali pode ser compreendido de onde vem os nomes usados nas pessoas nos dias atuais também (Relatório do Seminário da Etapa de Estudos da Especialização, 2014).

Txiarawa (2014), no mesmo processo, também apresenta uma análise de seus estudos com os sábios de sua comunidade. Segundo ele "com os sábios aprendi muito sobre a minha cultura, como por exemplo: pintura corporal, dança, conto, história e outros elementos culturais de relevância. Através da pesquisa, consegui entender por que hoje em dia os mais novos estão perdendo o valor de respeitar a família e de respeitar ao próximo. Na verdade, o contato com a sociedade envolvente ajudou enfraquecer nossa cultura (TXIARAWA, 2014).

Através destes mapas epistêmicos é possível verificar, claramente, o que Txiarawa afirmou, ou seja, o tamanho do estrago causado pela colonialidade do saber. A composição dos mapas revelou riquezas de sabedorias desconhecidas pelos próprios professores e pesquisadores Karajá. A partir dos estudos dos mapas, os professores têm mais possibilidades de aproveitar os saberes de seu povo na composição das matrizes curriculares e de tomarem decisão sobre quais projetos vão fazer parte delas. $O$ es- tudo dos mapas também favoreceu o estabelecimento de diretrizes educativas importantes na articulação da escola com outros espaços de práticas educativas e de produção de saberes, apontando para novas possibilidades de letramento pelos conhecimentos indígenas

\section{ESTICAR}

Como se pode perceber, a base epistêmica em tela aponta para novas concepções acerca da educação, como se vê na expressão atualização cultural e mapa epistêmico, e também indica outras maneiras de se produzir e difundir o conhecimento, que deve estar em movimento. Ela indica ainda a proposição de novas metodologias e dinâmicas pedagógicas, presentes nos temas contextuais e nos projetos extraescolares.

Um dos aspectos mais marcantes em sua constituição, como se mencionou acima, é a ideia de conexão entre os domínios da vida, em detrimento de uma epistemologia eurocêntrica que tende a fragmentar e isolar elementos. Neste sentido a armação das relações é fundamental para o entendimento de outras epistemologias. O verbo esticar, usado pelos alunos do Núcleo Takinahaky, aponta para este processo de associação entre domínios e desvela uma característica de uma pedagogia indígena presente, ao menos, nas ações do NTFSI.

O verbo esticar aponta, então, para múltiplos sentidos e as ações indicadas por ele parecem evidenciar operadores importantes da pedagogia indígena em tela. Em primeiro lugar, ele pode indicar uma ação que é efetivada no plano geográfico. Isto quando define um movimento entre dois lugares, por exemplo, entre a aldeia e Goiânia, onde estudam. Em seguida, define também uma 
ação social, quando estende a rede de relações entre sujeitos, como mencionou Yahé.

Além disso, esticar define igualmente uma ação simbólica. Isto ocorre quando marca uma ação que indica uma movimentação entre ideias, que representam itens importantes do universo em questão. Dodanin, por exemplo, também comentado, associa o verbo esticar ao tema da sustentabilidade, presente em um repertório da educação contemporânea. Segundo ele, seu projeto sobre utensílios tradicionais evidencia isso, pois sem esteira, por exemplo, não há casamento, não há festa, não há Krahô.

O verbo esticar, portanto, traz à tona uma dinâmica em fluxo, que tem relação com a noção de movimento e parece ser o operador da teoria pedagógica indígena. Segundo o mesmo Dodanin, a escola que movimenta é a escola viva, em oposição à escola não indígena (Etapa de estudos em Terra Indígena Krahô, 2013).

\section{AJUNTAR}

Nesta dinâmica de esticar e atualizar o conhecimento, percebe-se também uma relação particular entre saberes distintos indicando uma dinâmica interepistêmica. A ideia não é afirmar e reificar práticas classificadas enquanto tradicionais e eliminar condutas ditas não indígenas. A dinâmica proposta aponta para uma rearticulação de saberes, realizada com base nos saberes indígenas, mas que leva em consideração outros modos de se pensar e produzir o mundo. É como postula Luciano Baniwa quando fala do manejo de mundos da Escola Baniwa (2014).

Deve-se lembrar, então, que trata-se de um rearranjo entre os conhecimentos, já que nem tudo pode ir para a escola. Além disso, a natureza complexa da educação intercultural pede, cada vez mais, referências capazes de reconhecer os conhecimentos construídos em outras lógicas, em outras matrizes, com outros registros, com os saberes pertencentes ao mundo da oralidade. Muitos deles, inclusive, perdem substância quando transferidos para a escrita, pois não precisam da escrita alfabética para sobreviver, nem tão pouco da qualificação científica para validá-los. Seu verdadeiro registro se dá no fazer, no movimentar e na transmissão de geração a geração, revelando conexões governadas por outras racionalidades.

Neste contexto, o termo ajuntar, observado igualmente no discurso de professores indígenas, aponta para o sentido da ação acima comentada. Segundo Pereira (2015) que fez seu mestrado acerca de elementos constituintes do NTFSI,

pude perceber como o ajuntar do aluno xavante é importante para compreensão de uma realidade dinâmica e articulada entre o mundo indígena e não indígena. 0 que quero ressaltar é que os indígenas com quem convivi sempre procuraram ajuntar ou melhor colocar no mesmo status os conhecimentos dos dois mundos (indígena e não indígena), por isso a importância desta categoria (pp. 105-106).

\section{ALGUMAS CONSIDERAÇÕES}

A partir especialmente da década de 2000, abre-se então a possibilidade de uma universidade que em alguns casos e espaços recebe, escuta, acolhe e dialoga com populações que possuem outras epistemologias, como a Universidade das Quebradas, o Encontro de Saberes e o NTFSI. Como se vê o 
NTFSI é uma experiência inovadora na academia brasileira, pois, dentre outros aspectos, permite o surgimento de um novo repertório conceitual para se pensar a educação formal, os métodos, a pesquisa e a universidade.

Fica evidente igualmente que as políticas públicas de operacionalização de cursos específicos para a formação superior indígena constituem ações complexas e estimuladoras, em muitos casos, com implicações positivas nas diversas comunidades e universidades do país. Ao mesmo tempo, estas experiências trazem desafios políticos e epistêmicos centrais para a consolidação de novos paradigmas educacionais e societários.

No caso aqui tratado emerge uma nova base epistêmica que pode, se levada politicamente a sério, estabelecendo novas relações, métodos e perspectivas em relação à produção de conhecimento e espaços de convivência. Para Vitarelli (2017)

De certa forma, o conceito de parceiro comunitário quebra esquemas binomiais de pensamento único, dando origem a dispositivos e estruturas dialógicas que constroem sentidos, práticas e conhecimentos. Este é o desafio das epistemologias do sul, de um pensamento descolonial que refuncionaliza a dinâmica do conhecimento e do poder à luz de uma interação diferente dos atores ( $p$. 49).

Este processo de transformação pode ser observado igualmente em outros centros latino-americanos. Segundo Lamarra (2007, p. 1)

A universidade na América Latina e Argentina atualmente tem sérios problemas políticos, de planejamento e de gestão e, portanto, desafios importantes. Na medida em que se vai resolvendo os problemas, pode-se desenhar os planos e programas necessários e pertinentes, e realizar as profundas reformas em sua gestão o que permitirá enfrentar desafios sociais e acadêmicos com sucesso.

Desta forma, uma questão chave das propostas do NTFSI é a das transformações. Transformações por que passam professores, escolas indígenas e a educação bilíngue intercultural, transformações por que passam as comunidades indígenas participantes do curso, transformações por que passa a questão indígena no país e, também, transformações da universidade.

É recorrente a afirmação de que a mudança na educação escolar indígena se reflete nas escolas citadas, na vida dos professores e na posição dos indígenas na sociedade brasileira. Note-se que a transformação também é visível nas práticas de sala de aula, desvelando novas formas de ensino e aprendizagem nas comunidades e indicando a construção da educação diferenciada comentada.

Na universidade abre-se a possibilidade de espaços pluriepistêmicos que subvertem à colonialidade do saber, processo comum em outros espaços universitários. Para Oyewumi, "as sociedades que experimentaram a colonização sofreram muitos efeitos negativos, alguns psicológicos, alguns linguísticos e alguns intelectuais. Mas nenhum talvez tenha sido menos estudado do que como a colonização subjuga o conhecimento e marginaliza epistemes locais. (2016, p. 1).

A UFG, no caso aqui tratado, portanto, tem a possibilidade concreta de produzir, conhecer e praticar outras pedagogias e modos de gestão, consolidando a prática de uma nova base epistêmica, referenciada em noções como esticar, ajuntar, mapa epistê- 
mico, atualização cultural, pedagogia da retomada, bilinguismo epistêmico e outras.

Neste sentido esta experiência problematiza o pensamento monocultural presente na universidade - e nas pessoas que comumente frequentam e se apropriam deste espaço e a discussão que perpassa o campo da educação escolar indígena se torna uma chance para que, se esticada, aponte para transformações mais abrangentes na contemporaneidade.

De outra forma, corre-se o risco, portanto, de que o potencial da universidade para a inclusão e o reconhecimento de uma sociedade pluriepistêmica sejam apagados, e que tais políticas, programas e ações voltados à educação para/da diversidade, ao não darem um real valor político e epistêmico a outras formas de letramento de mundo, reproduzam os mesmos pressupostos coloniais de sempre, ao imporem uma normatização baseada em uma matriz eurocêntrica de saber e poder.

Nesta direção, para Daniel Munduruku:

Se houve uma tentativa de rasgar nosso espírito modificado pelo espírito europeu, houve também - e ainda há - uma nova tentativa de sacrificar nossa escrita tradicional, nosso olhar próprio com a uma lógica cruel que descaracteriza e empobrece nossa gente. Falo da escola tal como ela existe hoje nos meios urbanos. Falo da lógica da diferença que tem habitado os discursos políticos nos últimos quinze anos e que serviu, de certa forma, para reafirmar nossa condição de subseres humanos na prosopopeia linguística dos discursos etno pedagógicos dos pariwat. (2009, p. 2).

Deve-se lembrar, então, como postula Spivak, sobre até que ponto há a possibili- dade, por parte do Estado e suas instituições, de uma escuta sensível e descolonizada, que estipule valores similares aos diversos saberes. Conforme a autora, mais do que saber quem pode falar na contemporaneidade, deve-se perguntar sobre quem vai escutar e como se escuta (SPIVAK, 2010, pp. 59-67)

Trata-se aqui então, igualmente, de uma crítica ao uso banal do conceito da interculturalidade. Se por um lado tais experiências buscam de alguma maneira compreender a realidade indígena e os caminhos de luta construídos coletivamente, deixam de lado, outras vezes, as diversas maneiras de viver, de lutar, de acreditar e de formular a educação que lhes interessa. Para Munduruku (2009), "ouso dizer que as pedagogias inclusivas não passam de arremedos na solução de um 'problema' indígena, pois elas salientam ainda mais a falta de uma real compreensão do que seja um povo indígena e suas verdadeiras necessidades" (p.2).

Estes questionamentos - e outros - evidenciam profundos desafios nas formulações e efetivações de tais programas e mesmo na concepção de outros modelos de educação. Os professores Karajá/Iny, por exemplo, no processo de constituição de um novo Projeto Político Pedagógico (PPP) para suas escolas, chegaram a conclusão de que a fundamentação dos documentos não pode ser só com palavras escritas, com teorias ocidentais, mas também pela inclusão dos seus pertencimentos estéticos, epistêmicos, culturais e espirituais. Contextualizaram seus PPPs nas matrizes culturais: família, ciclo de formação da pessoa Karajá/Iny, na musicalidade dos espaços sagrados, na arte, e na beleza estética das danças e das pinturas corporais.

É nesse sentido que Manaijè Karajá (2014) 
reivindica uma escola intercultural e transdisciplinar, pois, segundo ele, dentro da interculturalidade e da transdisciplinaridade, colocam-se desenhos, músicas, artes, pintura etc.

A natureza complexa da educação intercultural, enfim, pede essas outras referências. Pede o conhecimento construído em outras lógicas de produção e registros de conhecimentos, que, no caso, nunca podem ser disciplinados.

Para Walsh (2014)

São momentos complexos de hoje que provocam movimentos de teorização e reflexão, não movimentos lineares mas serpenteantes, não ancorados na busca ou no projeto de uma nova teoria crítica ou mudança social, mas na construção de caminhos - de ser, pensar, olhar, escutar, sentir e viver com sentido ou horizonte de(s) colonial (p.8).

Problematiza-se, assim, a própria universidade. Propõe-se uma pluriversidade, onde existam diversas possibilidades de ser e existir. Onde os distintos modos de ser se encontrem. Para Evandro Canela cuja trajetória acadêmica está relacionada à experiência do NTFSI, e em relação à educação intercultural, "quando a gente se acha, é bom demais".

\section{REFERÊNCIAS}

COELHO DE SOUZA, Marcela S. A vida material das coisas intangíveis. Em. COELHO DE SOUZA, M. S.; COFFACI DE LIMA, E. C. (Orgs.). Conhecimento e Cultura: Práticas de transformação no mundo indígena. Brasília: Athalaia. 2010 pp. 205-228.

Comitê Apinajé-Krahô, 2012. Relatório PI-
BID-Diversidade. Núcleo Takinahaky de Formação Superior Indígena. Universidade Federal de Goiás.

DIETZ, Gunther; GUILHERME, Manuela; SOUSA SANTOS, Boaventura de. 2016. Da universidade à pluriversidade: Reflexões sobre o presente e o futuro do ensino superior. Revista Lusófona de Educação, 31, 201212.

ENCONTRO DE SABERES: http://www.inctin clusao.com.br/encontro-de-saberes/encon tro-de-saberes. Último acesso em 10 de maio de 2018.

Etapa de Estudos em Terra Indígena. Comunicação oral. Aldeia Cachoeira/ TI Kraholândia. Núcleo Takinahaky de Formação Superior Indígena. Universidade Federal de Goiás. Maio de 2013.

Etapa de Estudos em Terra Indígena. Comunicação oral. Aldeia Mariazinha/ TI Apinajé. Núcleo Takinahaky de Formação Superior Indígena. Universidade Federal de Goiás. Maio de 2012.

Etapa do Curso de Especialização em Educação Intercultural e Transdisciplinar: gestão pedagógica. Comunicação oral. Núcleo Takinahaky de Formação Superior Indígena/UFG/Goiânia. 10 a 15 de abril de 2014. HERBETTA, Alexandre. A dinâmica dos temas contextuais e as transformações na escola indígena. In: CASALI, Alípio; CASTILHO, Sueli. Diversidade na Educação: implicações curriculares, São Paulo: Editora da PUC, 2016.

KAMÊR, Julio.. Etapa de Estudos em Terra Indígena Apinajé, 2012. Comunicação oral. Aldeia São José. Núcleo Takinahaky de Form Comunicação oral ação Superior Indígena. Universidade Federal de Goiás.

KAMÊR, Julio. Xahtã mẽ pahte amnhĩ nhĩpêx ho hihtỳx: relações entre queimadas e cantorias no território Apinajé. Projeto Extraes- 
colar apresentado ao NTFSI/UFG, 2013. KARAJÁ, Manaijè. Relatório da III Reunião da Ação Saberes Indígenas na Escola. Goiânia: UFG/Núcleo Takinahakỹ de Formação Superior Indígena, 2014.

KARAJÁ, Txiarawa. Relatório da III Reunião da Ação Saberes Indígenas na Escola. Goiânia: UFG/Núcleo Takinahakỹ de Formação Superior Indígena, 2014.

LABORATÓRIO SOCIAL UNIVERSIDADE DAS QUEBRADAS. https://www.universidadedas quebradas.com. Acesso em: 10 de maio de 2018.

LAMARRA, N. F.; \& CÓPPOLA, N. Educación superior y calidad en América Latina y Argentina: los procesos de evaluación y acreditación. Buenos Aires: Eduntref, 2007.

LUCIANO BANIWA, Gersem José dos Santos. Educação para manejo do mundo. Entre a escola ideal e a escola real no Alto Rio Negro.Rio de Janeiro: LACED/CONTRA-Capa, 2014.

MIGNOLO, WALTER. Capitalismo y geopolítica del conocimiento. El eurocentrismo y la filosofia de la liberación en el debate intelectual contemporaneo. Ediciones del Signo, 2001.

MUNDURUKU, Daniel. A escrita e a autoria fortalecendo a identidade. Disponível em: $<$ http://pib.socioambiental.org/pt/c/iniciati vas-indigenas/autoriaindigena/a-escrita-e-aautoria-fortalecendo-a-identidade>. Acesso em: 30 dez. 2009.

NHINO, Emilio Dias Apinajé. Modos de exploração do babaçu na aldeia Mariazinha/Apinajé- entre o tradicional e o capital. 2016. Projeto Extraescolar. Núcleo Takinahaky de Formação Superior Indígena, Universidade Federal de Goiás, Goiânia, 2016. OLIVEIRA. Sinvaldo Karajá, Relatório do Seminário da Etapa de Estudos da Especialização. Goiânia: UFG/Núcleo Takinahakỹ de
Formação Superior Indígena, 2014. OYEWUMI, Oyronke. What gender is motherhood? Changing Yourubá ideals of power, procreation and identity in the age of modernity. UK: Palgrave Macmilian, 2016. PEREIRA, Dayane Renata Silva. Temos que ajuntar o conhecimento: professores indígenas e interculturalidade. 2015. Dissertação (Pós-Graduação em Antropologia Social) - Faculdade de Ciências Sociais, Universidade Federal de Goiás, Goiânia, 2015.

PIMENTEL DA SILVA, Maria do Socorro; FERNANDES, Joana, ROCHA, Leandro Mendes, LAZARIN, Marco, ROSA, Dalva. Projeto Político Pedagógico do Curso de Licenciatura Intercultural da UFG. Universidade Federal de Goiás, 2006.

PIMENTEL DA SILVA, Maria do Socorro; BORGES, Mônica Veloso (Orgs.). Educação intercultural experiências e desafios políticos pedagógicos. - Goiânia: PROLIND/SECAD-MEC/FUNAPE, 2013.

PIIKEN, Dodanin. Comunicação oral. Etapa de Estudos em Terra Indígena Krahô, 2013. Aldeia Manoel Alves Pequeno. Núcleo Takinahaky de Formação Superior Indígena. Universidade Federal de Goiás.

SPIVAK, Gayatri Chakravorty. Pode o subalterno falar? Minas Gerais: Editora da UFMG, 2010.

SOUZA SANTOS, B. La universidad en el siglo XXI. Para una reforma democrática y emancipadora de la universidad. Buenos Aires. LPP-Miño y Dávila Editores, 2005.

TAPIRAPÉ, Gilson. Comunicação oral. Etapa de Estudos em Goiânia, 2013. Núcleo Takinahaky de Formação Superior Indígena.

TAPUIA, Wellington. Comunicação Oral. Etapa de Estudos da Especialização Educação Intercultural e Transdisciplinar. 2014. Goiânia. Núcleo Takinahaky de Formação Superior Indígena. 
TXIARAWA KARAJÁ. Comunicação oral. Etapa de Estudos do Núcleo Takinahaky de Formação Superior Indígena. Goiânia. VITARELLI, Marcelo Fabian. Pensar las practicas pedagogicas em el sur. Buenos Aires: Editorial Autores de Argentina 2017. WAHUKÁ, Sinvaldo. Comunicação oral. Etapa de Estudos da Especialização Educação Intercultural e Transdisciplinar. 2014. Goiânia. Núcleo Takinahaky de Formação Superior Indígena.

WAMIMEN, Davi Chiavito Apinajé. Saúde contemporânea Apinajé: origens, razões e impactos do alcoolismo e da obesidade entre os Panhi. Projeto Extraescolar. Núcleo Takinahaky de Formação Superior Indígena. Universidade Federal de Goiás, 2016.

WALLERSTEIN, Immanuel. Las incertidumbres del saber. Gedisa editorial, 2004.

WALSH, Catherine. Pedagogias decoloniales: practicas insurgentes de resistir, (re) existir y (re) vivir. Serie Pensamiento Decolonial, 2013.

WALSH, Catherine. Lo pedagógico y lo decolonial: Entretejiendo caminos. Querétaro, Colec vo Zapateándole al mal gobierno. noviembre de 2014.

YAHÉ, Renato. PIIKEN, Dodanin. Comunicação oral. Etapa de Estudos em Terra Indígena Krahô, 2013. Aldeia Manoel Alves Pequeno. Núcleo Takinahaky de Formação Superior Indígena. Universidade Federal de Goiás. 